\title{
Temporal and interindividual variation in erythrocyte zinc-protoporphyrin in lead exposed workers
}

\author{
P Grandjean, P J Jørgensen, S Viskum
}

\begin{abstract}
Nineteen male workers from a factory making lead batteries participated in monthly blood tests to follow the effects of decreasing exposures to lead. The overall average blood lead (B Pb) concentration was $1.95 \mu \mathrm{mol} / 1$ $(40 \mu \mathrm{g} / 100 \mathrm{ml})$, but a significant decrease was seen over the one year study period. The relation to erythrocyte zinc-protoporphyrin (ZPP) concentration showed considerable scatter and only marginal improvement of the relation was obtained when each ZPP result was compared with the average $\mathrm{B} P \mathrm{~Pb}$ concentration during the previous four months. On an individual basis, five men showed a considerable decline in ZPP following decreases in $\mathrm{B} \mathbf{P b}$ concentration. In five other subjects with similar decreases in $\mathrm{B} \mathrm{Pb}$, no change in ZPP concentration was seen. These two groups were similar with regard to haemoglobin concentration, initial $\mathrm{B} \mathbf{P b}$ concentration, and age, but differed in duration of exposure. $A$ longer exposure time and presumably, therefore, larger body burdens of lead seemed to prevent the expected decrease in erythrocyte ZPP.
\end{abstract}

Excess exposure to lead may reduce the lifespan of erythrocytes and inhibit biosynthesis of haem. ${ }^{1}$ Low haemoglobin concentration and anaemia have been documented in heavy lead exposures, but haemoglobin concentrations in male lead workers are usually within normal ranges when blood lead $(\mathbf{B ~ P b})$ concentrations do not exceed $2.9 \mu \mathrm{mol} / 1(60 \mu \mathrm{g} / 100$ $\mathrm{ml}){ }^{2}$ One of the lead induced effects on haem

Department of Environmental Medicine, Odense University, Odense, Denmark

P Grandjean

Department of Clinical Chemistry, Odense University Hospital, Odense, Denmark

P J Jorgensen

Department of Occupational Medicine, Sønderborg Hospital, Sønderborg, Denmark

$S$ Viskum biosynthesis is inhibition of the insertion of iron into the protoporphyrin molecule, resulting in the formation of zinc-protoporphyrin (ZPP), which then forms a stable binding with the globin. ${ }^{3}$ The erythrocyte concentration of ZPP should, therefore, represent a biochemical effect of lead during the life span of the erythrocyte population, that is, the past four months. Concentration of ZPP can be rapidly measured by front face fluorometry ${ }^{4}$ and this measurement has therefore been recommended for surveillance of populations exposed to lead. ${ }^{24}$

The correlation of ZPP concentrations with $\mathrm{B} \mathrm{Pb}$ concentrations has shown considerable scattering, however, and some inconsistencies between different cross sectional studies. ${ }^{25}$ Such variability could be related to irregular levels of exposure that would result in changes in the $\mathrm{B} \mathrm{Pb}$ concentrations and $\mathrm{ZPP}$ as a longer term average would tend to be more stable. Also, analytical imprecision could play a part ${ }^{6}$ and individual differences in iron state $^{7}$ and ferrochelatase activity ${ }^{8}$ could be of importance.

We have examined $\mathrm{ZPP}$ and $\mathrm{B} \mathrm{Pb}$ concentrations in a group of workers exposed to lead over a one year period to evaluate the significance of temporal changes in exposure to lead.

Materials and methods

Nineteen male employees, mean age 32 (range 2249), at a factory manufacturing lead batteries agreed to participate in a study of exposure to lead and its early effects. The total number of employees at the plant is 120 ; the low participation rate was due to the fact that $\mathrm{B} \mathrm{Pb}$ monitoring was already provided and because the present study also required repeated and lengthy examinations. The range of duration of exposure to lead at the beginning of the study was from 4 to 139 months, the median being 96 months. Previous measurements showed past time weighted average $\mathrm{B} \mathrm{Pb}$ concentrations below $2.9 \mu \mathrm{mol} / 1$ in all workers, but a few analyses were above $4.0 \mu \mathrm{mol} / 1$. Fifteen of the subjects had an alleged alcohol consumption of four drinks or less a week, and eight were non-smokers.

A total of 11 monthly blood samples were scheduled from September to August (sampling was not scheduled in December); during this period, the 
three week summer vacation in July represented an exposure free interval before the last two blood collections. Blood collection generally took place on five consecutive days; the interval between monthly samplings was in most cases four to five weeks.

Blood samples for lead analysis were taken in vacutainer tubes with sodium heparin (dark blue stoppers; Becton-Dickinson, Rutherford, NJ, USA) under conditions minimising the risk of contamination. The samples were frozen at $-20^{\circ} \mathrm{C}$ until analysis. Analysis of $\mathrm{B} \mathrm{Pb}$ was carried out by electrothermal atomic absorption spectrometry. ${ }^{9}$ We used a Perkin-Elmer model 5000 instrument with Zeeman background correction, graphite furnace HGA-500, and autosampler AS-40 (Perkin-Elmer, Norwalk, CT, USA). All results were read against a blood based standard curve with standard reference material SRM 955 (US National Institute of Standards and Technology, Gaithersburg, MA, USA) as primary standard. Seronorm trace elements 901, 902, and 903 (NycoMed, Oslo, Norway) were used as quality control materials. The analytical imprecision was $10 \cdot 5,2 \cdot 7$, and $2 \cdot 6 \%$ at $\mathrm{B} \mathrm{Pb}$ concentrations of $0.25,1.64$, and $3.00 \mu \mathrm{mol} / 1$ respectively. The assigned values of $0.3,1.6$, and $3.2 \mu \mathrm{mol} / 1$ suggested an acceptable accuracy for the lead determinations.

Concentrations of ZPP were measured in oxidised fresh blood on an Aviv haematofluorometer (Aviv, Lakewood, NJ, USA).$^{10}$ In the absence of reference materials, calibration slides provided by the manufacturer were read before and after each analytical series; all results were within the expected variation of less than $3 \%$. In an interlaboratory comparison study organised by the Danish National Institute of Occupational Health, satisfactory results were obtained (J M Christensen, unpublished results). As the instrument measures the ZPP concentration in relation to haemoglobin concentration, the results are given in $\mu \mathrm{mol} / \mathrm{mol} \mathrm{Hb}(\mathrm{Fe})$; they can be converted to $\mu \mathrm{g} / \mathrm{g} \mathrm{Hb}(\mathrm{Fe})$ by dividing by 25 .

Blood haemoglobin concentration was measured

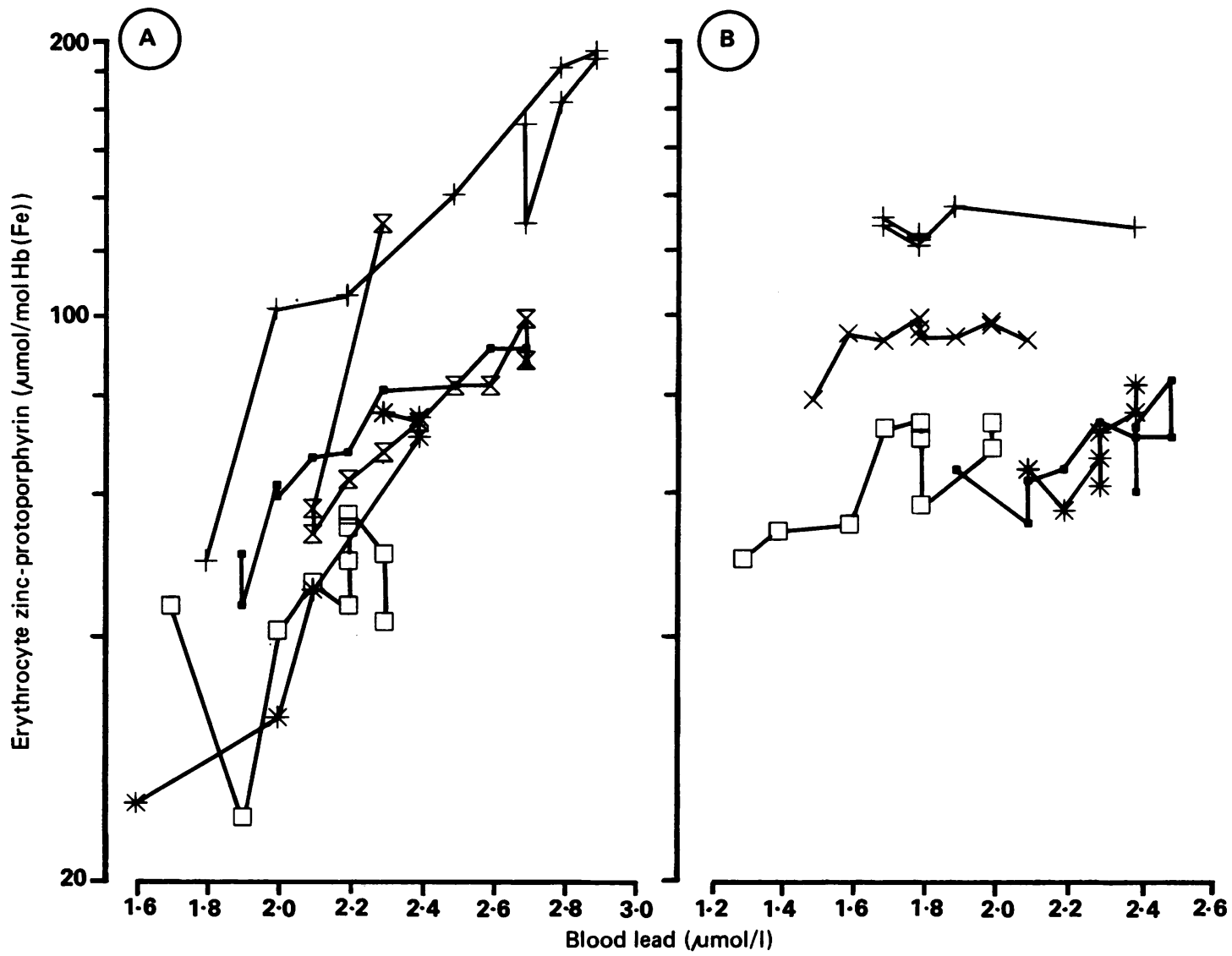

Relation between $B \mathrm{~Pb}$ and erythrocyte ZPP concentrations. Group $A$ : five male battery workers who showed clear decreases in $Z P P$ concentration as a result of declining $B$ Pb over a one year period. Group $B$ : five male battery workers who showed no change in $Z P P$ concentration despite decreases in $B P b$. Each $Z P P$ result is related to the average of at least three $B P b$ measurements during the preceding four month period. Results from adjacent months in the same subject are connected. 
by the cyano-haemoglobin method in the first two blood samples collected from all subjects. ${ }^{11}$

\section{Results}

At each examination, specimens were obtained from 14-18 of the participants. Samples were missed due to changes in shifts, sickness, and other absences. During the study period, improved hygiene practices resulted in a decrease in average $\mathrm{B} \mathrm{Pb}$ concentrations by about $20 \%$. Only a small part of this decrease was associated with the exposure free summer vacation. The overall average for $\mathrm{B} \mathrm{Pb}$ concentrations was 1.95 $\mu \mathrm{mol} / 1$. A parallel tendency was seen in average ZPP concentrations. On an individual basis, however, the relation between $\mathrm{B} \mathrm{Pb}$ and $\mathrm{ZPP}$ concentrations showed considerable scatter.

To refine the correlation between the two parameters of lead exposure, ZPP concentration was compared with the average of at least three $\mathrm{B} \mathrm{Pb}$ results obtained at and during the four months before the current determination. This comparison was carried out for the 14 subjects with the largest sets of analytical results; only slight improvement in the correlation was obtained. Much of the scattering appeared to be related to individual differences in $\mathrm{B} \mathrm{Pb} \mathrm{ZPP}$ relations. Thus, five subjects (group $\mathrm{A}$ ) showed a reasonable correlation with parallel trends over the study period (figure (A)). Five other men with comparable changes in $\mathrm{B} \mathrm{Pb}$ concentrations (group B) did not show any major changes in ZPP concentration (figure (B)). In four cases the changes in $\mathrm{B} \mathrm{Pb}$ concentrations were too small over the study period to allow any assessment of the individual correlation with ZPP concentrations.

Available parameters for the two groups were compared (table). The only difference found was duration of employment. Thus a good correlation between $\mathrm{B} \mathrm{Pb}$ and $\mathrm{ZPP}$ concentrations was obtained only in those subjects (group A) with the shorter exposure period.

All haemoglobin results were within the reference range. No obvious association with $\mathrm{B} \mathrm{Pb}$ or $\mathrm{ZPP}$ concentrations could be found. Three men in group A showed slightly lower haemoglobin concentrations than the men in group B (table).

Comparison of two groups of five male battery workers with regard to age, duration of employment, $B \mathrm{~Pb}$, and haemoglobin concentrations

\begin{tabular}{|c|c|c|}
\hline & $\begin{array}{l}\text { Group A } \\
\text { (median (range)) }\end{array}$ & $\begin{array}{l}\text { Group B } \\
\text { (median (range) })\end{array}$ \\
\hline \multirow{4}{*}{$\begin{array}{l}\text { Age }(\mathrm{y}) \\
\text { Duration of employment } \\
\text { (months) } \\
\text { B Pb before the study } \\
\quad(\mu \mathrm{mol} / \mathrm{l}) \\
\text { B-haemoglobin }(\mathrm{mmol} / \mathrm{l})\end{array}$} & $27 \quad(24-32)$ & $37 \quad(22-38)$ \\
\hline & $(4-96)$ & $112(21-131)^{\star}$ \\
\hline & $2 \cdot 3 \quad(1 \cdot 1-2 \cdot 6)$ & $1 \cdot 8 \quad(1 \cdot 7-2 \cdot 6)$ \\
\hline & $9 \cdot 2(9 \cdot 0-10 \cdot 0)$ & $9 \cdot 5(9 \cdot 3-10.0)$ \\
\hline
\end{tabular}

${ }^{\star} \mathrm{p}=0.028$, one tailed Mann-Whitney $U$ test.

\section{Discussion}

Erythrocyte ZPP concentration has become a useful screening parameter because of the ease and speed of measurement, and because capillary blood can be used. Increases in ZPP concentration are seen in iron deficiency, ${ }^{7}$ and in male workers the ZPP concentration is taken as a reflection of occupational exposure to lead. ${ }^{24}$ Because of the widespread use of this test, its validity must be carefully scrutinised.

Cross sectional comparisons with $\mathrm{B} \mathrm{Pb}$ concentration may not give a fair estimate of the correlation. The $\mathrm{B} \mathrm{Pb}$ concentration generally reflects the balance between uptake and excretion of lead and the deposition and release from storage depots in the body; with an average half life of lead in the blood compartment of about 30 days, $\mathrm{B} \mathrm{Pb}$ concentration is usually a good indicator of current lead exposures. ${ }^{1}$ By contrast, concentration of ZPP is believed to reflect the average effect of lead in bone marrow during the previous four months. ${ }^{3}$ Increases in concentrations of $\mathrm{B} \mathrm{Pb}$, however, may not be reflected in ZPP concentrations until about three weeks later and decreases can be delayed by several weeks. ${ }^{12} 13$

When correlating ZPP concentrations to the average $\mathrm{B} \mathrm{Pb}$ concentrations during the previous four months, the relation should be influenced to a minimal degree by short term variations in occupational exposure to lead. A surprising degree of scatter was still apparent, however, in the group examined in the present study. As shown in the figure, two different patterns emerge when the parameters are compared on an individual basis over the study period.

The difference in exposure time between groups $\mathbf{A}$ and $B$ would suggest that differences in body burdens of lead may play a part. Conceivably, lead stored in bone may be released to the blood forming tissue in the bone marrow, thus preventing a decline in concentration of ZPP despite the decrease in $\mathrm{B} \mathrm{Pb}$ concentration caused by the reduced exposure.

The interindividual variations are large enough to advise against translating ZPP concentrations to approximate $\mathrm{B} \mathrm{Pb}$ results, except on an individual basis where the relation between the two parameters is known. The diagnostic validity of the two tests must also be considered, however; ZPP concentration may be a better predictor than $\mathrm{B} \mathrm{Pb}$ concentration for lead related kidney toxicity ${ }^{14}$ and dysfunction of the nervous system, ${ }^{15}$ but confirmation of these findings is lacking. Although the general tendency is to rely almost exclusively on $\mathbf{B ~ P b}$ determinations, ZPP analysis may be of independent diagnostic or prognostic value, particularly if this parameter predicts tissue lead burdens in target organs.

The analytical validity must also be taken into account. For example, increased S-bilirubin concentrations, rare cases of erythropoietic protoporphyria and fluorescence of drugs, and possible contaminants 
can result in variable and erroneously high ZPP readings on haematofluorometers. ${ }^{6}$ Also, the instrument reading is routinely standardised by the use of reference slides, rather than blood specimens, and valid quality assurance procedures must therefore be included to avoid analytical bias.

The present study has shown a considerable variation in individual susceptibility to lead, with some subjects reaching ZPP concentrations severalfold higher than others at the same $\mathrm{B} \mathrm{Pb}$ concentrations. This observation does not mean that the ZPP test should be abandoned. The analysis is useful in determining trends in individual long term exposures to lead. Also, ZPP concentration may have an independent diagnostic value, but this needs to be defined in detail.

This study was supported by the Working Environment Foundation.

Requests for reprints to: Dr P Grandjean, Institute of Community Health, J B Winsløwsvej 17, DK-5000 Odense C, Denmark.

1 US Environmental Protection Agency. Air quality criteria for lead. Research Triangle Park, NC: USEPA, 1986. (EPA/600/ 8-83/028dF.)

2 Grandjean P. Occupational lead exposure in Denmark. Br J Ind Med 1979;36:52-8.

3 Lamola AA, Piomelli S, Poh-Fitzpatrick MB, Yamane T, Harber LC. Erythropoietic protoporphyria and lead intoxication, the molecular basis for difference in cutaneous photosen- sitivity. II. Different binding of erythrocyte protoporphyrin to hemoglobin. J Clin Invest 1975;56:1528-35.

4 Blumberg WE, Eisinger J, Lamola AA, Zuckerman DM. Zinc protoporphyrin level in blood determined by a portable hematofluorometer: A screening device for lead poisoning. $J$ Lab Clin Med 1977;89:712-23.

5 Verschoor M, Herber R, Zielhuis R, Wibowo A. Zinc protoporphyrin as an indicator of lead exposure: precision of zinc protoporphyrin measurements. Int Arch Occup Environ Health 1987;59:613-21.

6 Grandjean P, Lintrup J. Sources of variation in fluorometry of zinc-protoporphyrin in blood. Scand J Work Environ Health 1981;7:311-2.

7 Jensen BM, Sando SH, Grandjean P, Wiggers P, Dalhøj J. Screening with zinc-protoporphyrin for iron deficiency in nonanemic female blood donors. Clin Chem 1990;36:846-8.

8 Sassa S, Granick S, Kappas A. Effect of lead and genetic factors on heme biosynthesis in the human red cell. Ann N Y Acad Sci 1975;244:419-40.

9 Fernandez FJ, Hilligoss D. An improved graphite furnace method for the determination of lead in blood using matrix modification and the L'vov platform. Atomic Spectroscopy 1982;3:130-1.

10 Grandjean P, Lintrup J. Erythrocyte-Zn-protoporphyrin as an indicator of lead exposure. Scand J Clin Lab Invest 1978; 38:669-75.

11 van Kampen EJ, Zijlstra WG. Standardization of hemoglobinometry. II. The hemiglobincyanide method. Clin Chim Acta 1961;6:538-44.

12 Cools A, Sallé HJA, Verberk MM, Zielhuis RL. Biochemical response of male volunteers ingesting inorganic lead for 49 days. Int Arch Occup Environ Health 1976;38:129-39.

13 Schlegel H, Kufner G. Long-term observation of biochemical effects of lead in human experiments. JClin Chem Clin Biochem 1979;17:225-33.

14 Lilis R, Valciukas J, Fischbein A, et al. Renal function impairment in secondary lead smelter workers: correlations with zinc protoporphyrin and blood lead levels. Journal of Enviromental Pathology and Toxicology 1979;2:1447-74.

15 Grandjean P, Arnvig E, Beckmann J. Psychological dysfunction in lead-exposed workers. Scand J Work Environ Health 1978; 4:295-303.

Accepted 31 October 1990 